\title{
A Modeling Approach for Farmland Protection Zoning Considering Spatial Heterogeneity: A Case Study of E-Zhou City, China
}

\author{
Jianhua $\mathrm{He}^{1,2}$, Xiaodong Guan ${ }^{3, *}$ and Yan Yu ${ }^{4}$ \\ 1 School of Resource \& Environment Science, Wuhan University, 129 Luoyu Road, Wuhan 430079, China; \\ hjianh@126.com \\ 2 Key Laboratory of Geographic Information Systems, Ministry of Education, Wuhan University, \\ 129 Luoyu Road, Wuhan 430079, China \\ 3 Department of Geography, Hong Kong Baptist University, Kowloon Tong, Kowloon, Hong Kong, China \\ 4 School of Resource \& Environment Engineering, Wuhan University of Technology, 122 Luoshi Road, \\ Wuhan 430072, China; yyhrose@126.com \\ * Correspondence: 16483677@life.hkbu.edu.hk; Tel.: +852-6704-9391
}

Academic Editor: Vincenzo Torretta

Received: 28 July 2016; Accepted: 13 October 2016; Published: 19 October 2016

\begin{abstract}
Farmland protection in China is facing multiple pressures, including urbanization, population growth and ecological degradation. Primary farmland zoning was introduced as a basic state policy to ensure national food security. Previous studies about "primary farmland zoning" have always taken the factors as global linear variables, neglecting the spatial heterogeneity of the study areas. Based on the Development Priority Zoning (DPZ) strategy, we present a zoning approach using Bayesian networks (BNs) for considering regional differences. The networks were developed using quantitative biophysical and economic variables from multi-scale and historical change data of farmland. The simulated results substantiate that this method can ensure the agricultural quality, stability and connectivity of primary farmland. Furthermore, it can further optimize the spatial allocation of primary farmland to meet the development conditions and trends of different sub-regions, promoting the balance between the farmland protection, urban development and ecological protection of certain regions.
\end{abstract}

Keywords: farmland preservation zoning; spatial heterogeneity; Bayesian network; multi-scale; land use change; China

\section{Introduction}

Sufficient farmland is of vital importance to national food security, environmental services, protection of rural amenities, planned development patterns and a healthy economy [1,2], and nowhere is this especially true than in China. After the reform, China has experienced decades of remarkable economic development accompanied by rapid population growth, which has directly resulted in a tremendous amount of farmland loss at a rate of decline of 6.8 percent annually [3]. By 1978, China's population had already reached 963 million, but there were only 173 million city-dwellers, accounting for $18 \%$ of the total. By 2015 , however, the proportion of city-dwellers increased to more than $56.1 \%$, and the total population increased to 1.375 billion. While this situation will continue, it is estimated that the overall population will exceed 1.45 billion, and the rate of urbanization will amount to $70 \%$ in 2030 (National Bureau of Statistics of PRC 2015). Moreover, $40 \%$ of the existing farmland faces the threat of ecological degradation, as more than 10 million hectares of farmland have been lost annually because of soil erosion (Mistry of Land Resource of China). The tripling pressures of population 
growth, urbanization and ecological destruction present an increasing challenge for China's farmland protection and food security.

Ensuring adequate food for its 1.3 billion people has become a top priority for China's policy. Various measures have been taken to tighten control over the conversion of high-quality farmland to non-agricultural purposes, i.e., commercial, industrial or residential. The Primary Farmland Protection Regulation (passed in 1994) and the New Land Administration Law (enacted in 1999) are the two most important legal documents for farmland protection [4]. The third round of the National Land Use General Plan (2006-2020) has definitively issued the warning line of 1.8 billion mu ( $1 \mathrm{ha}=15 \mathrm{mu}$ ) of farmland. As a national farmland protection strategy, primary farmland aims to zone and protect farmland with high productivity and control its conversion to non-agricultural uses strictly.

Farmland protection has received the considerable attention of research [5,6]. Most of these studies focused on the evaluation of the effectiveness and impacts of farmland protection policies [7-9], showing that the performances of these policies are unsatisfactory for meeting the requirements of farmland protection $[10,11]$. The lack of a spatially-explicit method for zoning primary farmland has been recognized as a major reason [2]. Land quality evaluation approaches, which can assess the productive potential and suitability of farmland [12,13], have been widely used in the farmland protection zoning and planning fields [14-16]. Currently, most of the primary farmland zoning methods are based on the evaluation of biophysical or locational conditions to maximize agricultural suitability and minimize development potential [17-19], i.e., the agricultural land evaluation and site assessment (LESA) system developed by the America Soil Conservation Service [20,21]. Some other researchers have incorporated spatial constraints in primary farmland zoning, improving the compactness of the farmland protection area $[2,22,23]$. However, there are three key issues neglected in these methods.

The first issue is the spatial heterogeneity of the study area. Primary farmland zoning is a process to coordinate the regional relationship between farmland protection, urban development and ecological protection [24]. This is especially obvious in China, which has the largest population and insufficient available land resources. As the disparity of natural conditions and the imbalance of the developing stage of the interior of regions, primary farmland zoning has notable regional characteristics. In this case, taking each factor of a primary farmland zoning model as a global linear variable will lead to a large deviation between simulation results and reality. This problem becomes more obvious in the Development Priority Zoning (DPZ) strategy, which was proposed by the Chinese government in the Chinese National 11th Five-Year Plan (The State Council, 2010). According to the DPZ strategy, a territory is divided into four parts by its development conditions and objectives. They are optimized development zones (OPZ), key development zones (KPZ), restricted development zones (RDZ) and forbidden development zones (FDZ). The DPZ strategy is an effective approach that aims to coordinate regional development and protection [25], to offer guidance for regional land use, including primary farmland protection [26]. Therefore, in the process of farmland protection zoning, regional differentiation should be addressed, and various effective factors should be designed in different DPZs.

The second issue is the hierarchy of farmland protection zoning. Farmland protection zoning is a multi-level decision-making process for cities in China. Firstly, the State Council determines the overall quota of primary farmland according to the situation of national food security, environmental protection and urbanization processes. Subsequently, the quota will be decomposed into lower-level governments from top to bottom in the five-level administrative chains (state, province, city, county and township) as a mandatory planning index of land use. Then, these decomposed quotas will be allocated into land use parcels and zoned primary farmland area at a county/township level jurisdiction. Therefore, for farmland protection zoning of a specified city, multi-level factors should be incorporated to acquire the spatial allocation of primary farmland parcels, including the suitability condition factors at the parcel level and socioeconomic factors at higher levels (county/township). However, present primary farmland zoning methods have always focused on factors from a single scale, which is inadequate for the Chinese hierarchical primary farmland zoning system. 
The third issue is the consideration of land use dynamics and how to maintain the stability of farmland protection areas. Farmland faces the risk of encroachment by rapid urban expansion and ecological restoration $[27,28]$. Primary farmland protection is a measure to balance regional urban development and the protection of farmland and the environment [2]. Considering the need for regional development potential and ecological protection, reasonable farmland protection should ensure the current quality and long-term stability of primary farmland, avoiding frequent adjustments of farmland protection sites. Incorporating the historical change process of farmland into the zoning model is significant for ensuring the stability of primary farmland.

The Bayesian networks (BNs) approach is a graphic model based on Bayesian inference, which can deduce the probabilistic relationships between explanatory variables and outcomes of interest with a mathematical foundation [29]. BNs are suited to analyze hierarchical problems because they allow the inclusion of hierarchical dependences [30]. This allows them to capture and shape the nonlinearity interactions between variables that are valuable for us to incorporate multi-level factors into primary farmland zoning models and analyze their effects for farmland change. Another significant advantage of BNs is their ability to incorporate prior knowledge with new quantitative evidence [31,32], which contributes to the successful application of BNs in land use change studies [33,34] and environmental analyses [35,36]. This advantage also allows us to combine the dynamic change of farmland in the study area (prior knowledge) with suitability conditions of land use parcels (new evidence) when optimizing the spatial allocation of primary farmland. In addition, as a non-parametric statistical tool, BNs contain both qualitative and quantitative variables [37], making it an appropriate tool for optimizing farmland protection zones using both types of biophysical and socioeconomic data from different scales.

Additionally, the spatial pattern of primary farmland should also be incorporated into primary farmland zoning. Generally, farmland area with a compact pattern is more efficient and productive [2], as it is beneficial for agriculture industrialization and mechanization operations [23]. Landscape indices are suitable for measuring the spatial pattern [38]. In this study, we used the concept of "connectivity" to evaluate the global spatial pattern of farmland and quantified it with the tools of Fragstats (Oregon State University, Corvallis, OR, USA).

The objective of this paper is to present an alternative approach to model the farmland protection zoning in China using Bayesian networks. Both the quantitative data of suitability conditions at the parcel level and socioeconomic factors at higher levels and historical change data of farmland were incorporated into the BN model. The zoning result was also modified by connectivity analysis to further optimize the spatial pattern of primary farmland protection. A case study is used to demonstrate the efficiency of the proposed model by using E-Zhou City of Hubei province as an example.

We organized the remainder of this article in the following manner. In Section 2, we present the modeling framework of farmland protection zoning, including the division of the study area and the structure and parameters of each model. The study area and data are depicted in Section 3. Then, the results of primary farmland zoning and discussions are elaborated in Section 4. Finally, this article ends with conclusions.

\section{Methods}

The simulating model developed to facilitate farmland protection zoning is illustrated in Figure 1. Three key issues are integrated: (1) Regional differentiation: We divided the study area into four parts according to the Development Priority Zones Plan, as differences of natural conditions and developing stage and objectives exist among various zones. Various independent factors were also designed for different zones; (2) Hierarchy of primary farmland zoning: Both the suitability factors at the parcel level and socioeconomic factors at the township level were involved in our zoning model; (3) Dynamic of farmland use: We obtained the historical change data by comparing the land use map of different years and divided them into three types based on the conversion forms. The optimizing approach of Bayesian networks (BNs) is adopted in each zone to simulate and predict the potential of primary farmland of each parcel. Finally, we optimized the spatial locations of farmland protection zones based on the values of "primary farmland potential" and connectivity analysis. 


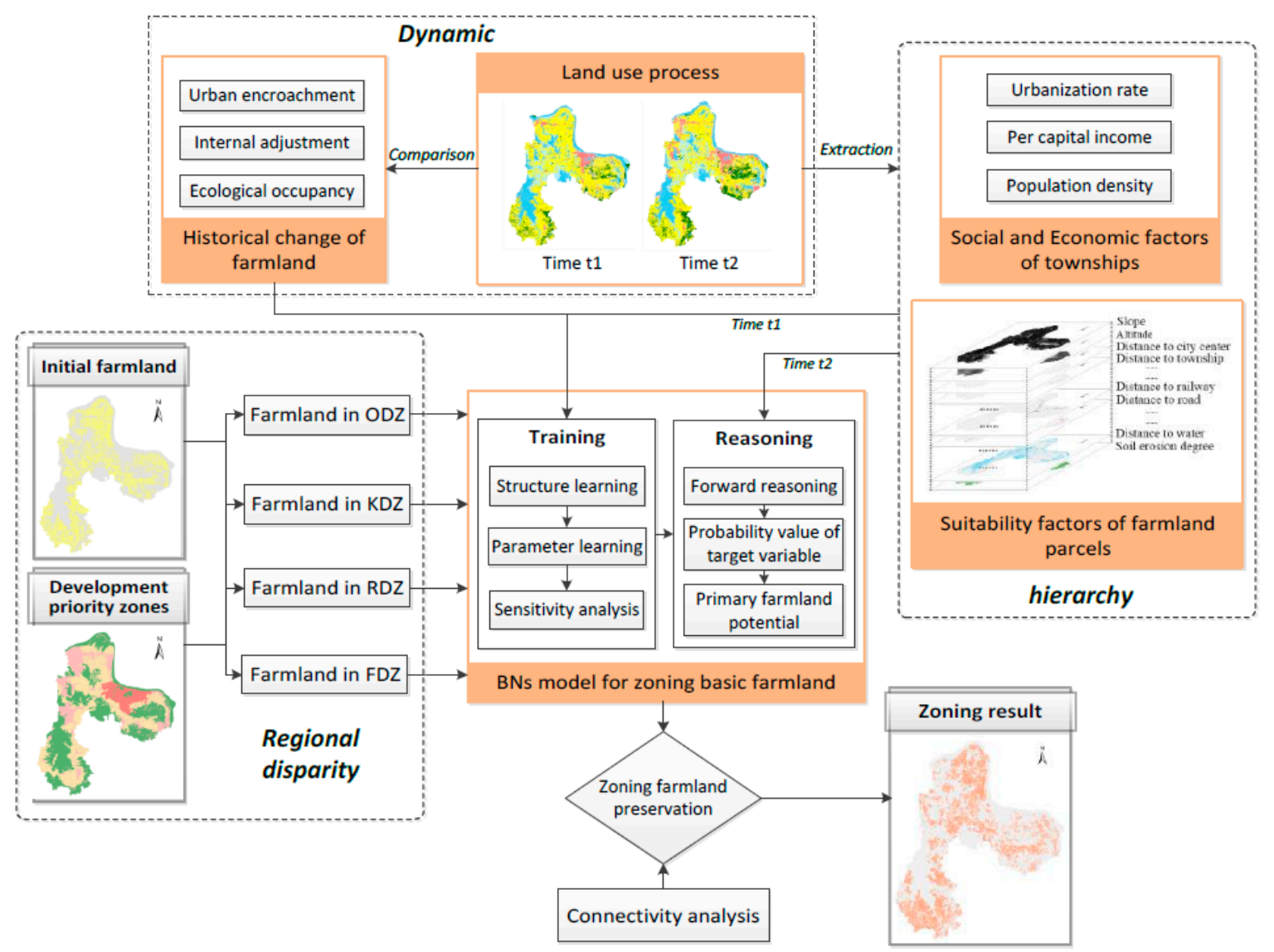

Figure 1. Model framework. OPZ, optimized development zones; KPZ, key development zones; RDZ, restricted development zones; FDZ, forbidden development zones.

\subsection{Variables' Description}

As shown in Table 1, the variables of the BN model consist of two levels: (1) the township level, including social and economic variables; (2) the parcel level, including suitability variables that reflect the cultivation quality and location of farmland and historical change variables, which are used to indicate the conversion type and trends of farmland.

At the parcel level, we used five biophysical variables to reflect the quality of farmland: "slope" and "altitude" for the terrain condition, "distance to water" for the irrigation condition, "erosion degree" for the soil condition and "soil level" for the productive potential. Five locational variables were considered to measure the location conditions of the farmland. In addition, the historical change process was classified into three types, representing different forms of farmland conversion. Meanwhile, we incorporated three socioeconomic variables at the township level, including "urbanization rate" for urban development, "per capita income" for economic development and "population density" for societal development.

All of the economic variables are involved in every BN model for four DPZs. However, different groups of suitability and historical change variables are incorporated into various models according to the regional characteristics of each zone: ODZ represents regions with a high land development density and lower environment capacity. The principle function of ODZ is to maximum economic growth [25], which always leads to urban encroachment of farmland. We selected four locational variables and one historical change variable, "urban encroachment", to model the conflict between urbanization and farmland protection. KDZ relates to regions with good resources and environmental conditions and relatively rapid economic development rates, which has the main function of promoting urbanization and accommodating the migration from rural areas. Two additional biophysical factors were added 
into the model to explain the farmland degradation of KDZ since we have observed marked "ecological occupancy" in this region.

In contrast, RDZ concerns regions with poor economic development foundations and weaker environment capacities. The principle of "protection first, moderate development" has a major objective for restoring the environment and providing a balanced population density. Land erosion and degradation become the main threat for primary farmland protection in this zone. Therefore, five biophysical factors are incorporated in this model. Lastly, FDZ refers to natural reserves, in the form of compulsory protection of ecological function and prohibition of any development activity contrary to this principle. This suggests that ecological restoration and afforestation will be dominant drivers of farmland loss. Thus, the variable of "distance to ecological forest" was added to this model on the basis of the RDZ model.

Table 1. Selection and description of variables.

\begin{tabular}{|c|c|c|c|c|c|c|c|}
\hline Scale & $\begin{array}{c}\text { Variable } \\
\text { Classification }\end{array}$ & Variable Name & ODZ & KDZ & RDZ & FDZ & Description \\
\hline \multirow{3}{*}{$\begin{array}{l}\text { Township } \\
\text { level }\end{array}$} & \multirow{3}{*}{$\begin{array}{l}\text { Socioeconomic } \\
\text { variables }\end{array}$} & Urbanization rate & $\sqrt{ }$ & $\sqrt{ }$ & $\sqrt{ }$ & $\sqrt{ }$ & $\begin{array}{c}\text { Proportion of } \\
\text { non-agriculture population }\end{array}$ \\
\hline & & Per capita income & $\sqrt{ }$ & $\sqrt{ }$ & $\sqrt{ }$ & $\sqrt{ }$ & Pure income per capita \\
\hline & & Population density & $\sqrt{ }$ & $\sqrt{ }$ & $\sqrt{ }$ & $\sqrt{ }$ & $\begin{array}{l}\text { Average population of per } \\
\text { square kilometer }\end{array}$ \\
\hline \multirow{14}{*}{ Parcel level } & \multirow{10}{*}{$\begin{array}{l}\text { Suitability } \\
\text { variables }\end{array}$} & Slope & & & $\sqrt{ }$ & $\sqrt{ }$ & Slope of farmland \\
\hline & & Altitude & & & $\sqrt{ }$ & $\sqrt{ }$ & Altitude of farmland \\
\hline & & Soil level & & & $\sqrt{ }$ & $\sqrt{ }$ & $\begin{array}{c}\text { Farmland productivity } \\
\text { potential }\end{array}$ \\
\hline & & Soil erosion degree & & $\sqrt{ }$ & $\sqrt{ }$ & $\sqrt{ }$ & $\begin{array}{l}\text { Soil erosion degree } \\
\text { of farmland }\end{array}$ \\
\hline & & Distance to water & & $\sqrt{ }$ & $\sqrt{ }$ & $\sqrt{ }$ & $\begin{array}{l}\text { Distance to nearest river, } \\
\text { lake or pool }\end{array}$ \\
\hline & & Distance to road & $\sqrt{ }$ & $\sqrt{ }$ & & & $\begin{array}{l}\text { Distance to nearest } \\
\text { main road }\end{array}$ \\
\hline & & Distance to railway & $\sqrt{ }$ & $\sqrt{ }$ & & & Distance to nearest railway \\
\hline & & Distance to city center & $\sqrt{ }$ & $\sqrt{ }$ & & & Distance to city center \\
\hline & & Distance to township & $\sqrt{ }$ & $\sqrt{ }$ & & & Distance to town center \\
\hline & & Distance to ecological forest & & & & $\sqrt{ }$ & $\begin{array}{l}\text { Distance to nearest } \\
\text { ecological forest }\end{array}$ \\
\hline & \multirow{3}{*}{$\begin{array}{l}\text { Historical change } \\
\text { variables }\end{array}$} & Urban encroachment & $\sqrt{ }$ & $\sqrt{ }$ & & & $\begin{array}{l}\text { Transfer from farmland to } \\
\text { construction land }\end{array}$ \\
\hline & & Internal adjustment & & & $\sqrt{ }$ & $\sqrt{ }$ & $\begin{array}{l}\text { Transfer from farmland to } \\
\text { other agriculture land }\end{array}$ \\
\hline & & Ecological occupancy & & $\sqrt{ }$ & $\sqrt{ }$ & $\sqrt{ }$ & $\begin{array}{l}\text { Transfer from farmland to } \\
\text { ecological land, including } \\
\text { water and unused land }\end{array}$ \\
\hline & Target variable & Primary farmland potential & $\sqrt{ }$ & $\sqrt{ }$ & $\sqrt{ }$ & $\sqrt{ }$ & $\begin{array}{l}\text { Potential of farmland as } \\
\text { primary farmland } \\
\text { preservation }\end{array}$ \\
\hline
\end{tabular}

\subsection{Model Learning and Reasoning}

Building a BN generally includes two steps: the construction of the network structure (directed acyclic graph, DAG) and the estimation of the parameters (conditional probability table, CPT). The network structure of each BN model was constructed based on the relationships between variables and modified it using empirical farmland zoning models. Then, the CPTs of the networks were learned using the expectation-maximization (EM) algorithm with the BNT toolbox in MATLAB 2012b.

For each BN model, taking the land suitability data, economic data at $t_{1}$ and farmland change as training data, we learned the parameters of the Bayesian network (CPT) using the EM algorithm (Figure 1). The interaction relations between the input variables and the target variable "primary farmland potential" were presented in the trained network. Then, adding the suitability and economic 
data of farmland parcels at time $t_{2}$ as new observed evidence into each network, we determined the maximum posterior probability value of "primary farmland potential" by forward reasoning.

Moreover, the influence of input variables on the target variable can be quantified through sensitivity analysis in Netica software [39]. The analysis result is expressed by variance reduction, which represents the magnitude of explanatory information that a variable imposes on another variable [30]. We analyzed the driving forces of farmland loss at different DPZs through sensitivity analysis of the target variable.

\subsection{Spatial Allocation of Primary Farmland}

Optimization of the spatial allocation of primary farmland needs to combine the primary farmland potential (including quality and stability of farmland) with the spatial pattern. Firstly, we selected the farmland parcels of all of the zones with larger potential values into initial primary farmland, ensuring that the total area is slightly greater than the quota (the quota has been assigned by upper level government). Then, we dissolved the adjacent farmland parcels into one patch. Farmland parcels within the larger patch are considered to have better connectivity. Finally, we iteratively selected the farmland patches with a larger area as the final protected farmland, until the total area is equal to the designed quota of primary farmland protection.

\section{Study Area and Data}

\subsection{Study Area}

E-Zhou city of Hubei province was selected as the typical study area because of its serious loss of farmland in recent years. From 2004-2013, the total area of farmland dropped from 7.44 down to 5.80 thousand hectares, while the urbanization rate increased from $48.77 \%-60.48 \%$. Several new development areas were established in optimized development zones (OPZ) and key development zones (KDZ), accompanied by urban sprawl (urban area rose from 46.2-60.1 $\mathrm{km}^{2}$ ) and economic growth (GDP increased from 13.04-63.09 billion yuan), at the price of 21.62\% arable land loss. As a central industrial city based on mining and metallurgy, rapid urbanization and industrialization have contributed to the great encroachment of farmland, making E-Zhou city a typical experiment area of farmland protection zoning study for the medium and small cities in central China (Figure 2).

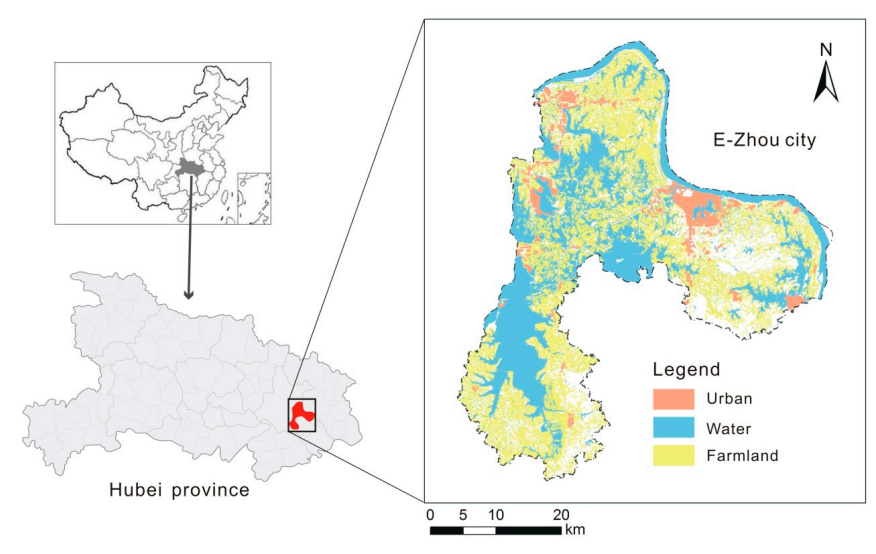

Figure 2. Study area.

\subsection{Data and Data Processing}

\subsubsection{Data}

Using 2004 as the baseline year $\left(t_{1}\right)$ and 2013 as the target year $\left(t_{2}\right)$, vector maps of land use in these two years were collected. We also obtained the socioeconomic data of each township from the 
"Statistical Yearbook of E-Zhou City" and acquired the raster maps of suitability variables through the "Euclidean distance" tool of ArcGIS9.3. Some of these base data and the Development Priority Zoning Plan of E-Zhou city are shown in Figure 3. We also collected the farmland protection plan, which will be used to validate our experiment results.

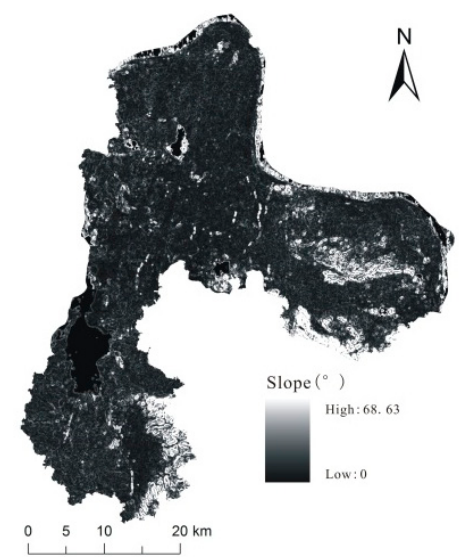

(a)

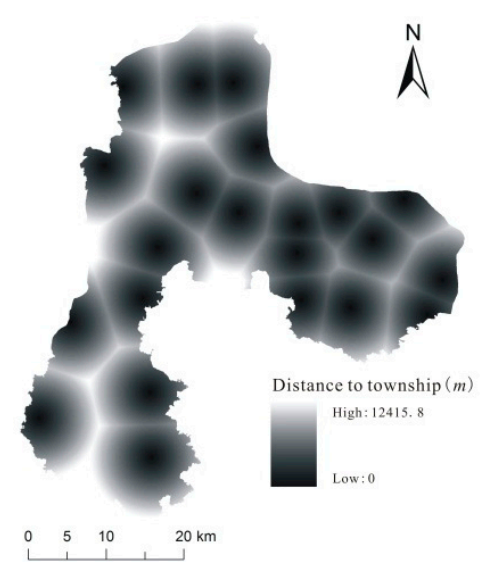

(d)

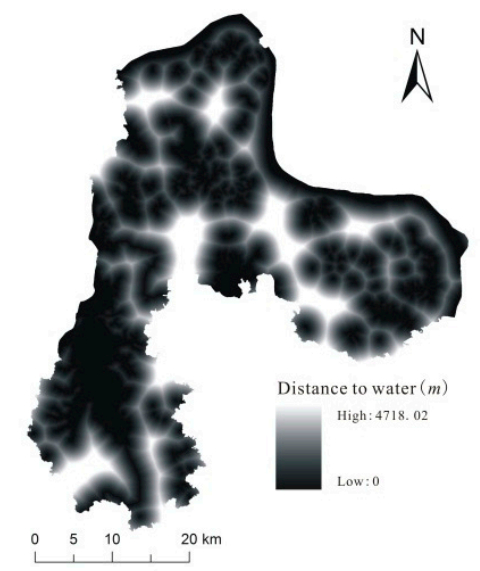

(g)

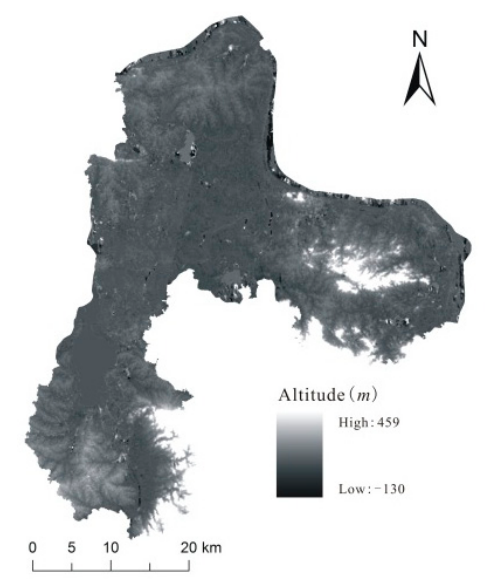

(b)

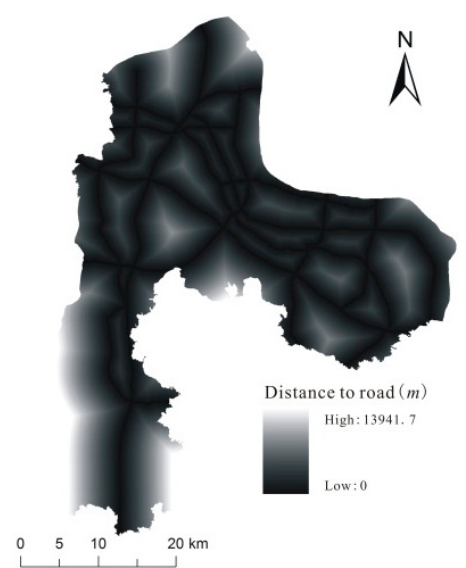

(e)

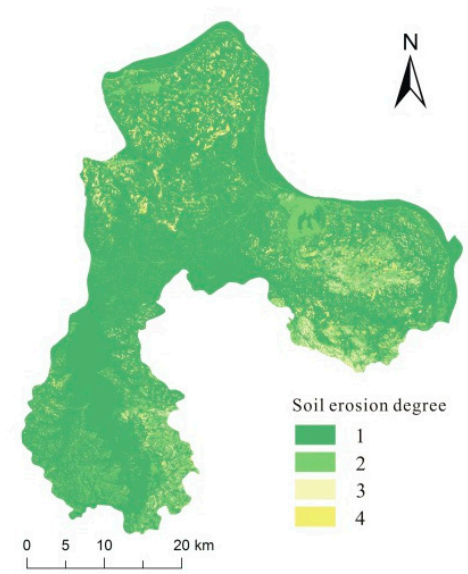

(h)

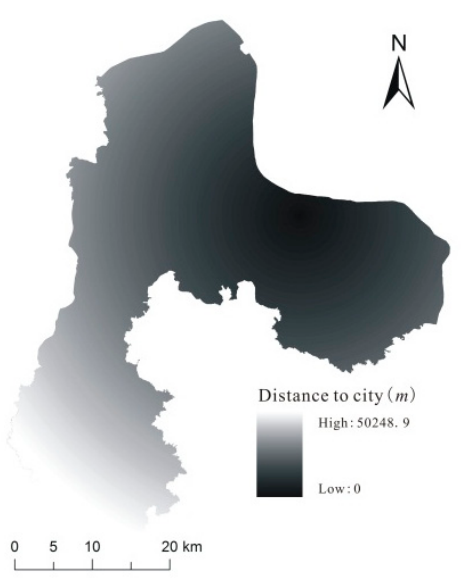

(c)

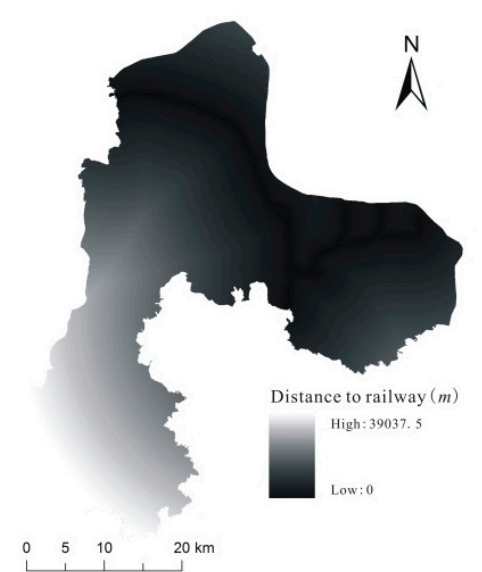

(f)

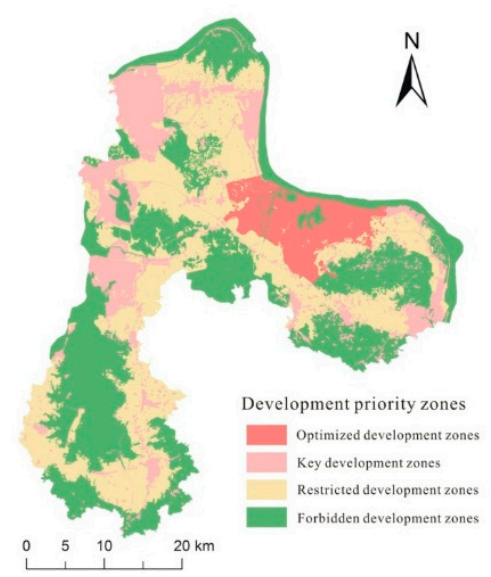

(i)

Figure 3. Base data: (a) slope; (b) altitude; (c) distance to city center; (d) distance to township; (e) distance to road; (f) distance to railway; (g) distance to water; (h) soil erosion degree; (i) development priority zoning. 


\subsubsection{Variables' Discretization}

To ensure the precision of sampling and network training, we created a total of 80,000 random points from the farmland parcels in the year 2004 and proportional distributed them by the area of each zone. Through spatial overlay analysis with the base data, we obtained the values of network variables for every random point. We also discretized the continuous values, as shown in Table 2.

Table 2. Discretization results for network variables.

\begin{tabular}{|c|c|c|c|c|c|c|c|}
\hline \multirow{2}{*}{ Variable Names } & \multirow{2}{*}{ Value Type } & \multicolumn{6}{|c|}{ Classification Code } \\
\hline & & 1 & 2 & 3 & 4 & 5 & 6 \\
\hline Urbanization rate $(\%)$ & Continuous & $\leq 0.05$ & $0.05-0.15$ & $0.15-0.5$ & $>0.5$ & & \\
\hline Per capita income $(\%)$ & Continuous & $\leq 0.75$ & $0.75-0.9$ & $>0.9$ & & & \\
\hline Population density (per square kilometers) & Continuous & $\leq 500$ & $500-1000$ & $>1000$ & & & \\
\hline Slope $\left({ }^{\circ}\right)$ & Continuous & $0-2$ & $2-5$ & $5-15$ & $>15$ & & \\
\hline Altitude (m) & Continuous & $\leq 15$ & $15-30$ & $>30$ & & & \\
\hline Soil level & Discrete & 1 & 2 & 3 & 4 & 5 & 6 \\
\hline Soil erosion degree & Discrete & 1 & 2 & 3 & 4 & & \\
\hline Distance to water $(\mathrm{km})$ & Continuous & $\leq 0.5$ & $0.5-1$ & $1-2$ & $>2$ & & \\
\hline Distance to road $(\mathrm{km})$ & Continuous & $\leq 0.5$ & $0.5-1$ & $>1$ & & & \\
\hline Distance to ecological forest $(\mathrm{km})$ & Continuous & $\leq 0.5$ & $0.5-2.5$ & $>2.5$ & & & \\
\hline Urban encroachment & Discrete & $\bar{Y}$ Yes & No & & & & \\
\hline Internal adjustment & Discrete & Yes & No & & & & \\
\hline Ecological occupancy & Discrete & Yes & No & & & & \\
\hline Primary farmland potential & Discrete & Yes & No & & & & \\
\hline \multicolumn{8}{|l|}{ ODZ } \\
\hline Distance to railway $(\mathrm{km})$ & Continuous & $\leq 1$ & $1-2$ & $>2$ & & & \\
\hline Distance to city center (km) & Continuous & $\leq 4$ & $4-8$ & $>8$ & & & \\
\hline Distance to town center $(\mathrm{km})$ & Continuous & $\overline{\leq 1} .5$ & $1.5-3$ & $>3$ & & & \\
\hline \multicolumn{8}{|l|}{ KDZ } \\
\hline Distance to railway $(\mathrm{km})$ & Continuous & $\leq 3$ & $3-10$ & $>10$ & & & \\
\hline Distance to city center (km) & Continuous & $\overline{\leq} 20$ & $20-30$ & $>30$ & & & \\
\hline Distance to town center $(\mathrm{km})$ & Continuous & $\leq 2$ & $2-4$ & $>4$ & & & \\
\hline
\end{tabular}

Too many intervals will drastically increase the complexity of BNs, as the CPTs of nodes increase exponentially with the number of intervals. To balance the precision and complexity of the BNs, we divided all of the continuous variables into three or four grades. Expert knowledge was considered when we determined the cut-off values, e.g., the slope discretization corresponds to the "Technical Regulations of the Second National Land Survey" of China. We set the values of farmland parcels that maintain stability from 2004-2013 as "yes" and the others as "no". In particular, we standardized the variable "per capita income" within the range $[0,1]$ before discretization, due to the huge growth of pure income per capita of E-Zhou city from 2004-2013, which would decrease the precision of BNs if discretized directly. Moreover, the distribution of ODZ farmland parcels is concentrated in the city center. As a result, we modified the discrete intervals of three nodes of the ODZ model to adapt the numerical range and improve the discretization efficiency.

\section{Results and Discussion}

\subsection{Results}

\subsubsection{BN Model Training Results}

The final network structure of each model is illustrated in Figure 4. The target variable "primary farmland potential" indicates whether the farmland parcel is fit for primary farmland protection. For three historical change variables, urban encroachment is affected by four locational variables; internal adjustment is determined by most of the biophysical factors, except distance to water; and ecological occupancy is influenced by slope, soil erosion degree and distance to water. The economic variables are related to "distance to city center" to reflect the impact of a city in terms of social and economic development. 
The initial probability distribution of all variables is shown in the resulting Bayesian networks (Figure 4). Twenty-six-point-four percent of ODZ and 40.1\% of KDZ farmland were encroached by urban expansion. Meanwhile, internal adjustment proportions of RDZ and FDZ farmland were $7.49 \%$ and $20.1 \%$. Nine-point-three percent of KDZ and FDZ and 12.2\% of RDZ farmland were occupied by ecological land.

The initial probability distributions of economic variables are different among the four BN models. For ODZ and KDZ, the proportions of the urbanization rate greater than $50 \%$ were $20.7 \%$ and $24.8 \%$, respectively. However, the proportions for RDZ and FDZ were both lower than $2 \%$, and the proportions of population density greater than 800 were the same. More than $50 \%$ per capita income of KDZ was greater than 0.9 , whereas this proportion was lower than $30 \%$ for other zones. For suitability factors, the soil erosion degree of FDZ was worse than that of KDZ and RDZ, and the soil level of RDZ was better than that of FDZ. Simultaneously, the average slope and altitude of FDZ were higher than those of RDZ.

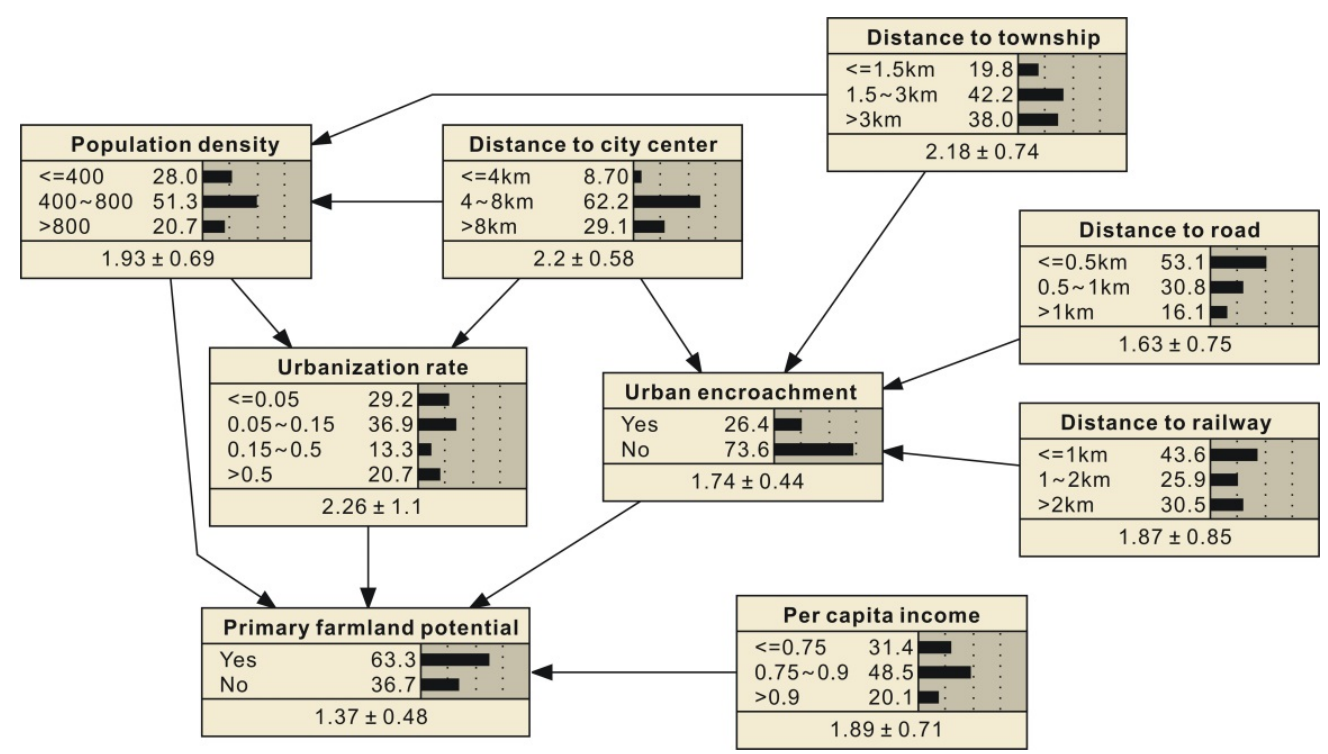

(a)

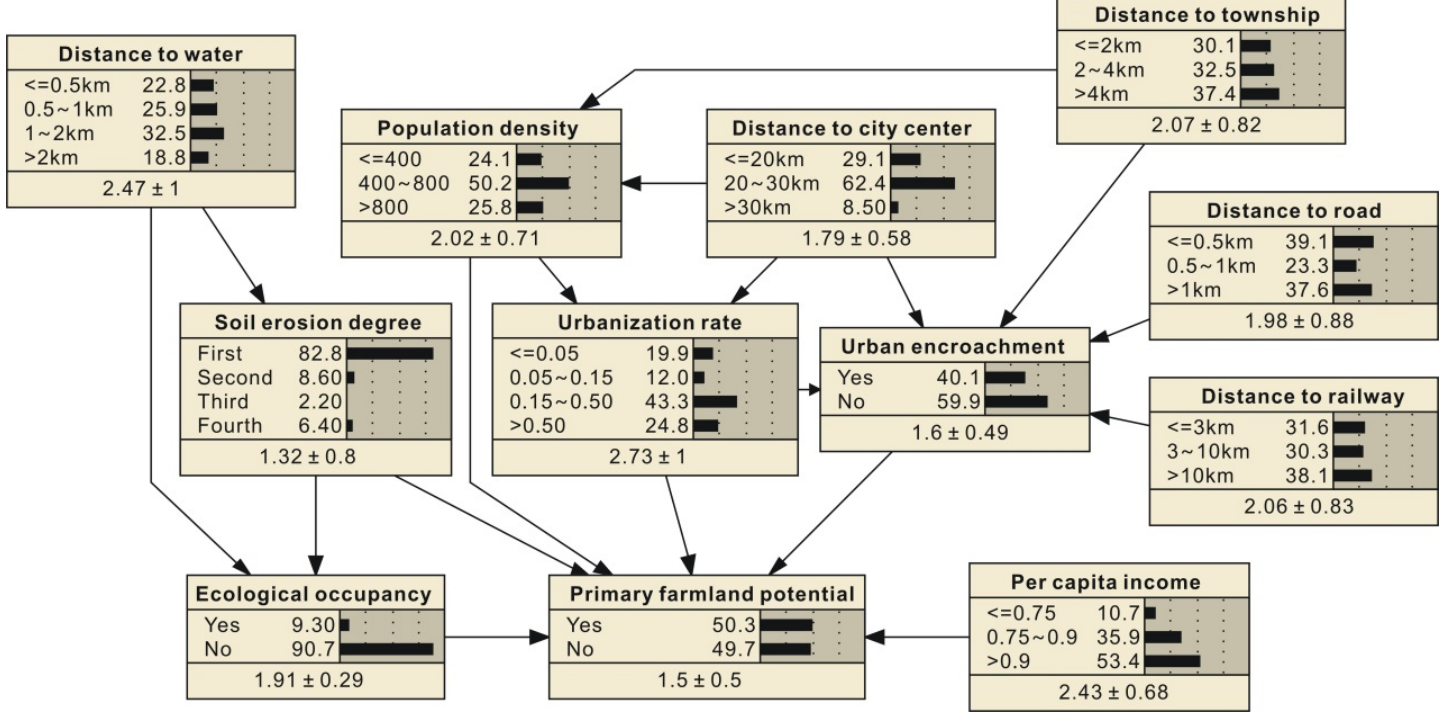

(b)

Figure 4. Cont. 


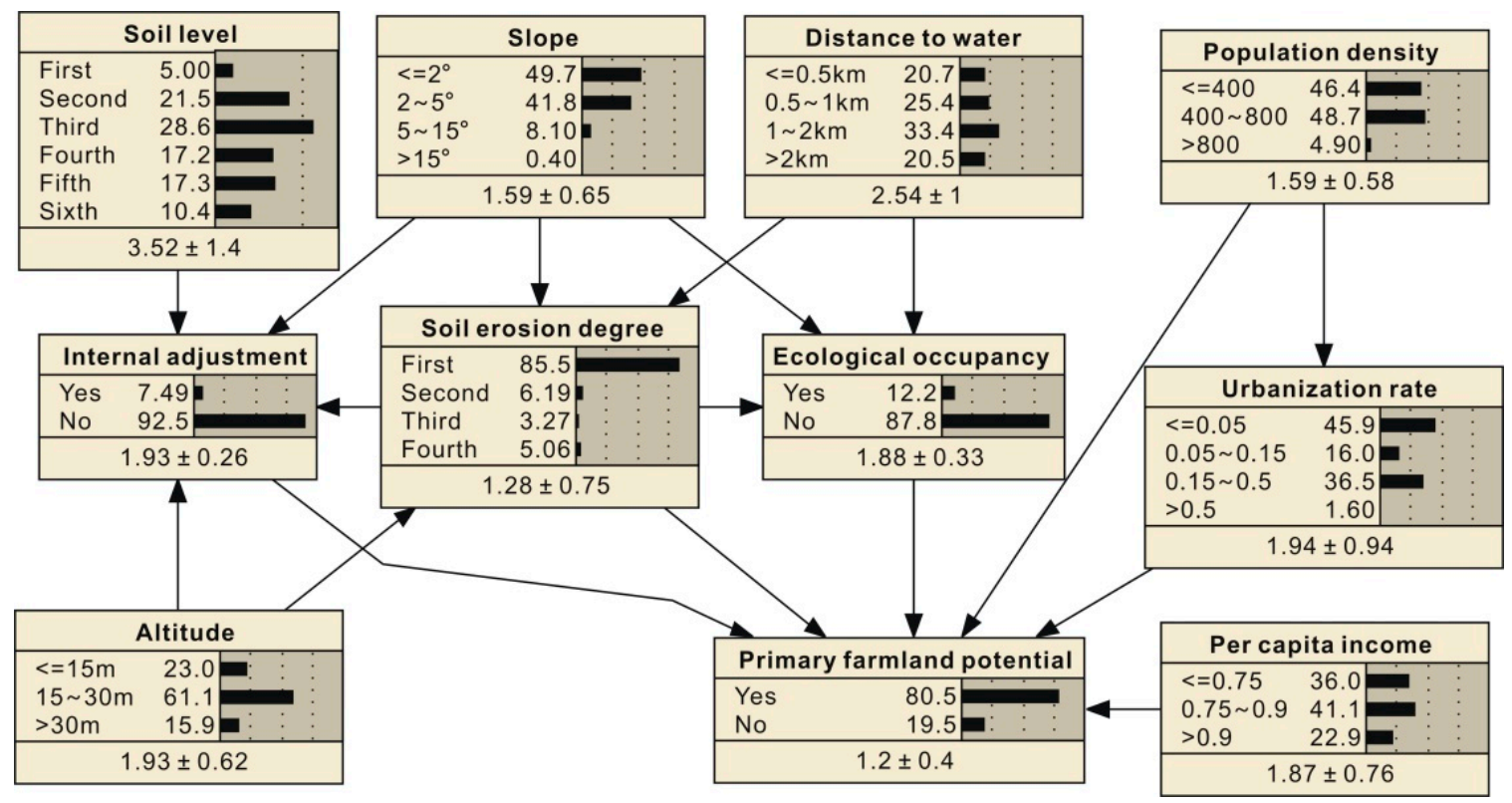

(c)

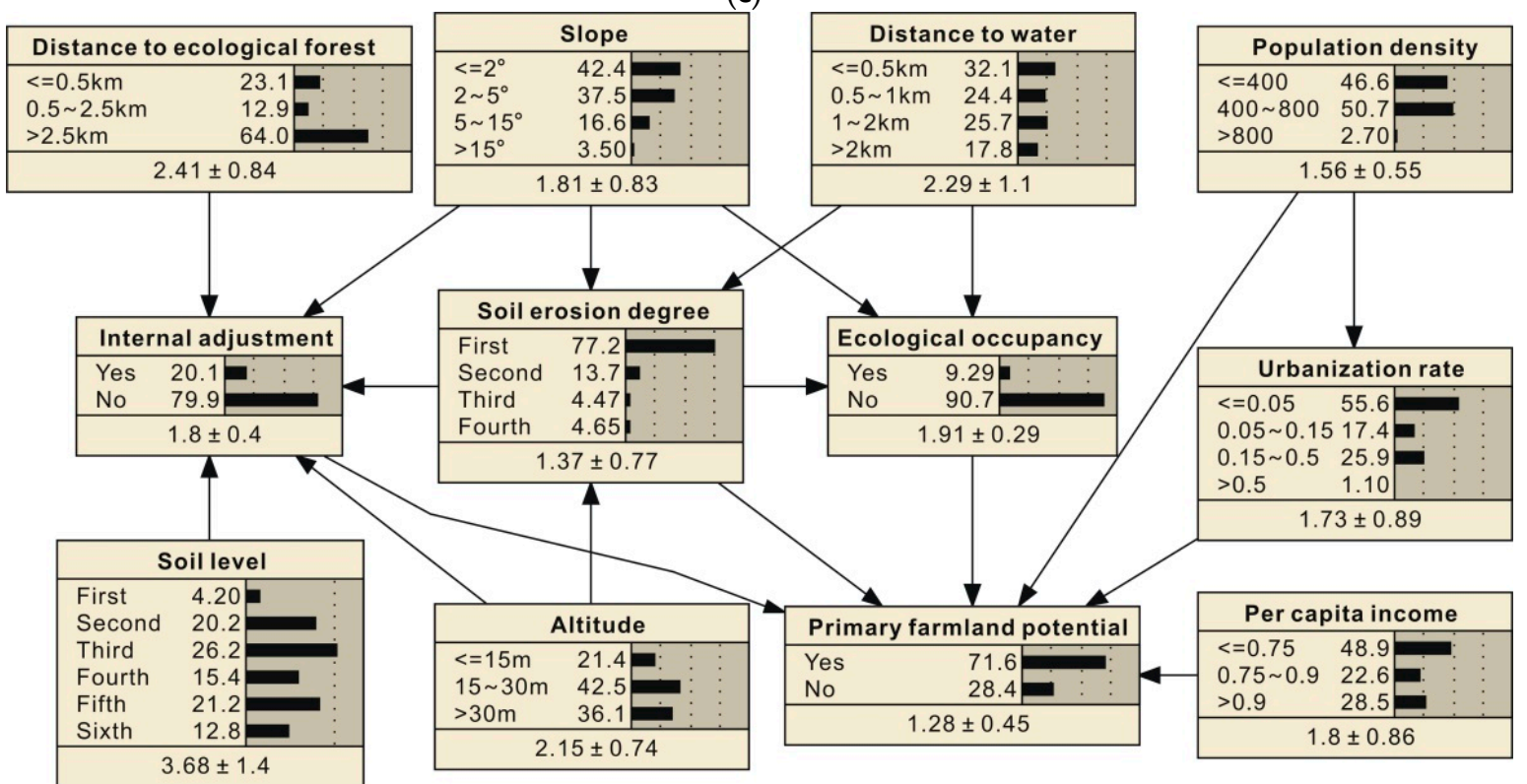

(d)

Figure 4. The resulting Bayesian networks: (a) optimized development zones; (b) key development zones; (c) restricted development zones; and (d) forbidden development zones.

\subsubsection{Sensitivity Analysis Results}

We calculated the sensitivity of the target variable in relation to all other variables. As shown in Table 3, historical change variables always have the greatest influence on the potential value of prime farmland, such as urban encroachment (with variance reduction $10.1 \%$ and $26.8 \%$ for OPZ and KDZ, respectively), internal adjustment (24.5\% for FDZ) and ecological occupancy (29.7\% for RDZ). Except for the historical variables, the distance to the city center has dominate influence $(0.34 \%)$ on the primary farmland potential of ODZ. All of the economic variables of ODZ have a variance reduction of more than $0.15 \%$. For the KDZ model, the distance to the city center also contributes the most $(0.34 \%)$ to the reduction of primary farmland potential, and the distance to the road/railway both have a significant effect on the target variable, with variance reductions of $0.14 \%$ and $0.13 \%$. Economic 
variables of the RDZ model have a strong influence on the target variable, with additional influential variables including slope, altitude, soil erosion degree and distance to water. For FDZ, in addition to the economic variables, all of the suitability variables have a significant impact on the sensitivity reduction of primary farmland potential, especially soil erosion degree and altitude, with variance reductions of $2.13 \%$ and $1.68 \%$, respectively.

Table 3. Sensitivity analysis result of the target variable.

\begin{tabular}{|c|c|c|c|c|c|}
\hline \multirow{2}{*}{ Variable Classification } & \multirow{2}{*}{ Variable Name } & \multicolumn{4}{|c|}{ Variance Reduction (\%) } \\
\hline & & OPZ & KPZ & RDZ & FDZ \\
\hline \multirow{10}{*}{ Suitability variables } & Slope & & & 0.34 & 0.84 \\
\hline & Altitude & & & 0.40 & 1.68 \\
\hline & Soil level & & & 0.07 & 0.23 \\
\hline & Soil erosion degree & & 0.10 & 0.15 & 2.13 \\
\hline & Distance to water & & 0.01 & 0.50 & 0.19 \\
\hline & Distance to road & 0.05 & 0.14 & & \\
\hline & Distance to railway & 0.04 & 0.13 & & \\
\hline & Distance to city center & 0.34 & 0.34 & & \\
\hline & Distance to township & 0.06 & 0.01 & & \\
\hline & Distance to ecological forest & & & & 0.64 \\
\hline \multirow{3}{*}{ Socioeconomic variables } & Urbanization rate & 0.21 & 0.13 & 0.46 & 0.18 \\
\hline & Per capita income & 0.16 & 0.17 & 1.56 & 0.70 \\
\hline & Population density & 0.26 & 0.05 & 1.06 & 0.40 \\
\hline \multirow{3}{*}{ Historical change variables } & Urban encroachment & 10.1 & 26.8 & & \\
\hline & Internal adjustment & & & 9.3 & 24.5 \\
\hline & Ecological occupancy & & 1.6 & 29.7 & 13.0 \\
\hline
\end{tabular}

\subsubsection{Scenario Simulation Results}

We collected the values of suitability variables for every farmland parcel in 2013, which were added to the trained network as new evidence. The maximum posterior probability value of "primary farmland potential" for each farmland parcel was obtained by forward reasoning. According to its land use plan (E-Zhou Land Use Plan 2006-2020), the quota of primary farmland for E-Zhou city is $451.28 \mathrm{~km}^{2}$. Therefore, we first selected the farmland parcels with primary farmland potential values greater than 0.70 and obtained an initial farmland protection area of $493.26 \mathrm{~km}^{2}$, which exceeds the quota demand slightly.

Then, through connectivity analysis of initial primary farmland, small farmland parcels were merged into bigger patches. We iteratively selected farmland patches with a greater size as final primary farmland, until the total area reached $451.28 \mathrm{~km}^{2}$. We also tried zoning the primary farmland without spatial constraints, which resulted in a fragmented spatial pattern of primary farmland, as shown in Figure 5.

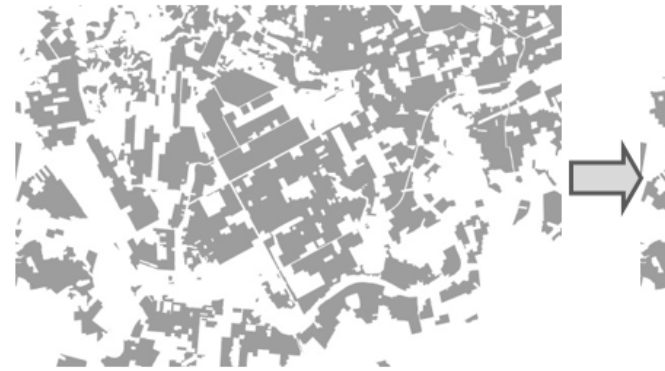

(a)

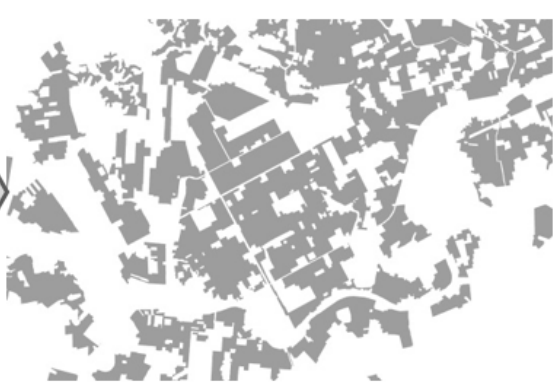

(b)

Figure 5. The comparison of primary farmland zoning results: (a) without spatial constraints; and (b) with spatial constraints. 
The scenario simulation result of zoning primary farmland is shown as Figure 6. Some of the farmland parcels were abandoned in the process of zoning primary farmland, as their potential values of primary farmland were low. We selected 11 typical areas of ordinary farmland from four development priority zones to analyze the main reasons for their low primary farmland potential. The utilization grade of most farmland parcels in the R1 area is fourth or fifth, which suggests low grain productivity potential. Farmland in the sites of F1 F4 has serious soil erosion and a high slope, making them difficult to cultivate. In contrast, the natural conditions of farmland in the sites of K1 K4 are relatively fine. However, they are still abandoned as they are located adjacent to urban construction land and traffic lines, easily encroached by urban expansion. The farmland parcels in $\mathrm{O} 1$ and $\mathrm{O} 2$ are also not suitable as primary farmland because they are too close to the city center.

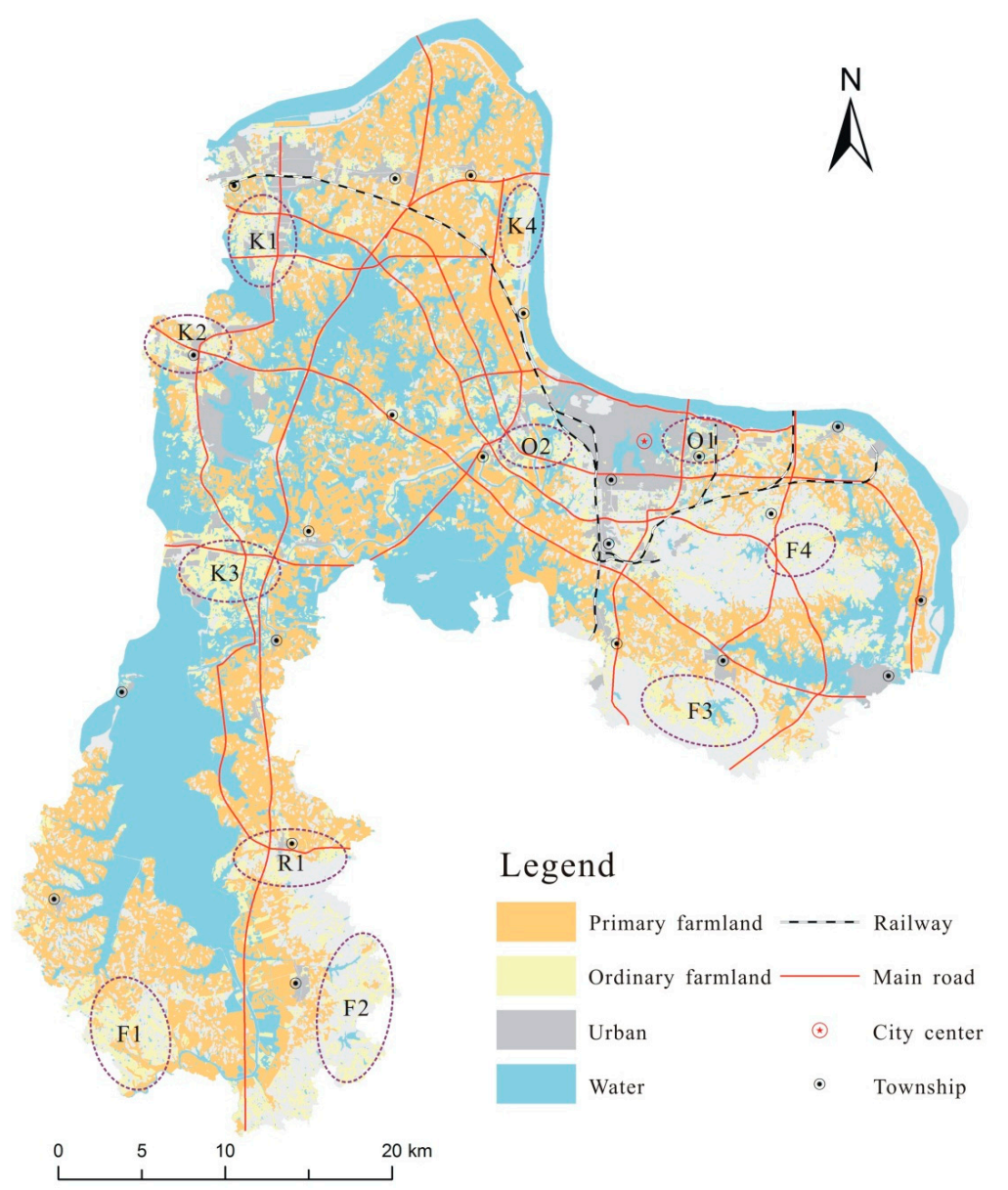

Figure 6. The result of zoning primary farmland. Note: the orange parcels represent primary farmland, while light yellow parcels represent ordinary farmland that was not selected into primary farmland preservation, the main area of which is encircled by purple ellipses (Typical areas of ordinary farmland: $\mathrm{O} 1 \sim \mathrm{O} 2$ in $\mathrm{ODZ}, \mathrm{K} 1 \sim \mathrm{K} 4$ in KDZ, $\mathrm{R} 1$ in RDZ and F1 F4 in FDZ).

\subsubsection{Assessment Results}

To further assess the proposed models, we compared the spatial distribution of zoning primary farmland with primary farmland planning. As shown in Figure 7, the traditional planning result, which was based on the land evaluation method, abandoned most farmland parcels close to urban or transportation facilities, such as the areas $\mathrm{O} 1 \sim \mathrm{O} 2$ and $\mathrm{K} 1 \sim \mathrm{K} 4$. This is most beneficial for urban development and easy to understand, as China is a country with rapid urbanization. However, in the meantime, the planning result reserved most of the farmland parcels with poor natural conditions (F1 F4, R1), leading to the obvious decline of the overall quality of primary farmland. Fortunately, 
our zoning result of primary farmland has identified farmland with both great natural conditions and lower occupancy risk priority, such as the areas O3 O5 and K5 K7.

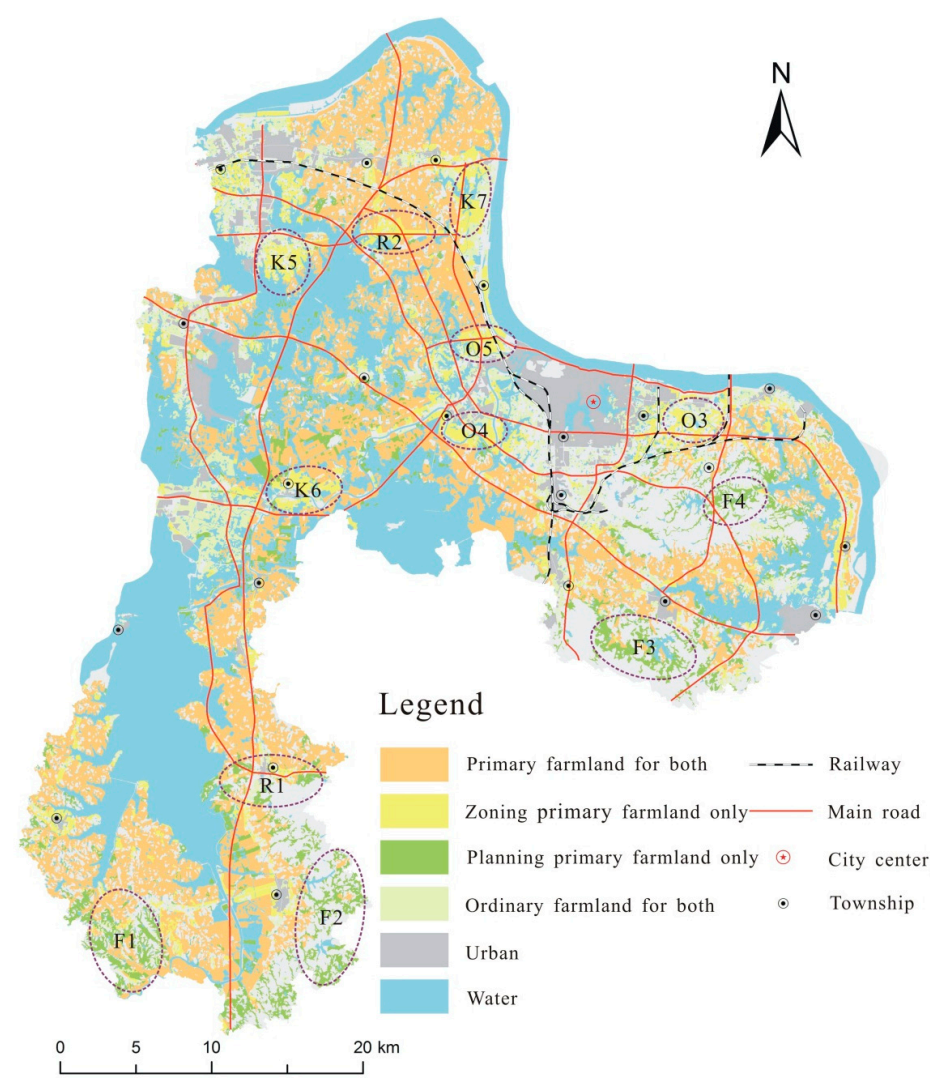

Figure 7. The comparison of zoning and planning primary farmland. Note: the orange parcels represent primary farmland that was included by both zoning and planning results; yellow parcels represent primary farmland that only the zoning result has; while green parcels represent primary farmland included by the planning result only.

\subsection{Discussion}

In this paper, we divided the farmland parcels of the study area into four zones according to the Development Priority Zoning Plan of E-Zhou city. The survey data reflected the disparity of natural and socioeconomic conditions between various zones (Figure 4). The urbanization rates of ODZ and KDZ are greater than those of RDZ or FDZ, which indicates that RDZ and FDZ accommodate most of the agricultural population and, thus, require large amounts of farmland. Meanwhile, compared with RDZ and FDZ, KDZ also has a higher average population density. This can be explained by the immigration from FDZ and ODZ and, simultaneously, will lead to a sharp increase in construction land demand at KDZ. Additionally, FDZ has worse natural conditions than RDZ, including soil level, soil erosion degree, slope and altitude. This makes it seriously sensitive to ecological deterioration. In order to mitigate this situation, a series of measures has been taken in this area by local government, including ecological forest preservation zoning and "grain for green" projects.

In total, $26 \%$ of farmland was converted to other land from 2004-2013 in our study area. The severe farmland loss has significant regional differentiation and different driving forces among various zones (Table 4). The most serious loss of farmland occurred at KDZ, mainly caused by urban encroachment. Sensitivity analysis also demonstrated that urban expansion is the main driver of farmland instability at KDZ. RDZ has the minimum farmland loss, of which ecological occupancy is the main driving force. In addition to economic reasons, soil salinization caused by adjacent lakes and unqualified terrain conditions contributed most to the conversion of farmland to ecological 
land. Internal adjustment occurred most at FDZ, and sensitivity analysis results suggested that land degradation caused by serious soil erosion, steep terrain and reforestation near the ecological forest are reasonable explanations. The increase of ecological forest area from 2004-2013 that we observed from vector land use data also supports this hypothesis.

Table 4. Comparison of farmland loss and zoning for four development priority zones

\begin{tabular}{ccccc}
\hline Zones & Farmland Loss Ratio & Main Driver & Primary Farmland Ratio & $\begin{array}{c}\text { Average Area of Primary } \\
\left.\text { Farmland Parcels } \mathbf{( k m}^{\mathbf{2}}\right)\end{array}$ \\
\hline ODZ & $36.7 \%$ & Urban encroachment & $44.70 \%$ & 0.46 \\
KDZ & $49.7 \%$ & Urban encroachment & $38.86 \%$ & 0.23 \\
RDZ & $19.5 \%$ & Ecological occupancy & $88.21 \%$ & 1.25 \\
FDZ & $28.4 \%$ & Internal adjustment & $68.74 \%$ & 0.91 \\
\hline
\end{tabular}

Similarly, the sensitivity of suitability factors differs among zones. For example, distance to $\mathrm{road} /$ railway at KDZ has a greater influence than that at ODZ. Because land development intensity of KDZ is usually lower, the urbanization of this zone always depends more on transportation infrastructure. In addition, the influence of soil erosion degree on primary farmland potential increased at KDZ-RDZ-FDZ. Along with the decrease of environmental capacity, the influence of soil erosion on farmland degradation gradually became more prominent. Farmland protection of E-Zhou city is facing the dual pressures of urban expansion and ecological deterioration. Consideration of regional differences is necessary and meaningful to highlight the regional characteristics and disparity for farmland protection.

The simulation result of primary farmland zoning also indicates that development priority zone strategies have an impact on farmland protection zoning (Table 4). KDZ has the lowest farmland protection ratio, which is consistent with the need for rapid urbanization and industrialization and the duty to accommodate migration from rural. RDZ shares most of the primary farmland protection task, as it has minor development pressure and should thus follow the principle of "protection first". Three-point-one-five thousand hectares of farmland are located in this region, and $88.21 \%$ of them were identified as primary farmland. The productivity of primary farmland in RDZ was improved through removing low-yielding farmland parcels like the R1 site. Ninety-eight-point-seven percent of primary farmland in RDZ has a gradient of less than five degrees, and $80 \%$ of these has a water source within $2 \mathrm{~km}$, which is beneficial to farming and irrigation. As shown in Figure 8, while the spatial pattern of primary farmland at ODZ and KDZ is more fragmented, RDZ has the most compact farmland protection area, with the average parcel size of $1.25 \mathrm{~km}^{2}$, suitable for the development of the industrialization and mechanization of agriculture.

A combination of multi-level effective factors is necessary and valuable for primary farmland zoning. All of the economic variables are significant driving forces for every zoning model (except population density of the KDZ model). This is not surprising because economic conditions determine the primary farmland quota distribution among higher administrative units. Meanwhile, economic factors performed differently among regions. They have the greatest influence on the primary farmland potential of RDZ and the least influence in the KDZ model (Table 3). The main reason is that the serious imbalance between urbanization and industrialization development degree among restricted development zones has increased the impact of economic conditions on primary farmland potential.

Moreover, the incorporation of historical change data revealed the farmland dynamic of different zones and exploring the impact of economic and suitability factors. This is helpful for ensuring that the zoning results correspond to the regional land use change trend, improving the stability of primary farmland and promoting the coordination between urban development, ecological restoration and farmland protection (Figure 6). For example, the primary farmland of ODZ and KDZ abandoned the farmland parcels adjacent to present urban construction land $(\mathrm{O} 1 \sim \mathrm{O} 2, \mathrm{~K} 1 \sim \mathrm{K} 4)$ to leave room for urbanization. Instead, farmland of high quality and relatively lower development potential is included in the primary farmland $(\mathrm{O} 3 \sim \mathrm{O} 5, \mathrm{~K} 5 \sim \mathrm{K} 7)$ to ensure that the quantity of the farmland protection is 
reached, as well as improving the overall quality of primary farmland. Moreover, some of the farmland parcels at FDZ are also unsuitable for farmland protection, due to their poor terrain conditions, lower productivity potential or close proximity to ecological forest. These are also key areas for the ecological reforestation of E-Zhou city, filled with land reclamation and reforestation.

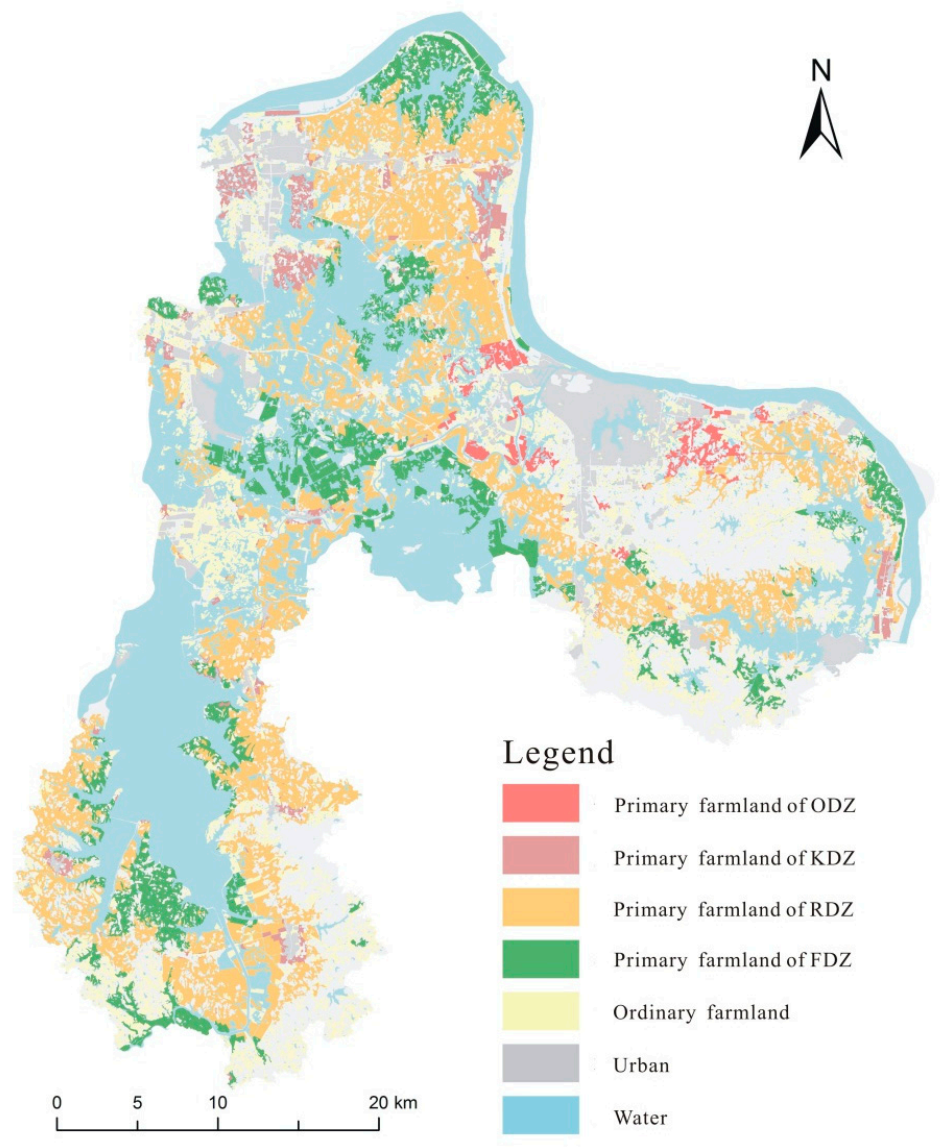

Figure 8. The spatial allocation of zoning primary farmland at four zones.

Due to the lack of scientific zoning methods, traditional primary farmland zoning often emphasized quantity over quality, by simply including farmland with unqualified natural conditions, which is unreasonable and unfavorable for the protection of farmland and ecology (Figure 7). The zoning result of farmland protection considering regional differences has successfully removed the farmland parcels with lower potential, including the areas with poor agricultural conditions, lower productivity potential or lack of long-term stability (Figure 6), because of the incorporation of social and economic data, suitability conditions and the historical change of farmland in the farmland protection zoning process.

\section{Conclusions}

Zoning primary farmland is of great importance for not only farmland protection and national food security, but also urban development and ecological protection. We divided the farmland of E-Zhou city into four zones according to the development priority zoning plan and developed a zoning model considering regional differences to facilitate primary farmland zoning. Considering the hierarchy, dynamics and connectivity of farmland, we realized the spatial allocation of primary farmland with Bayesian networks. Building various BN models at different zones has markedly improved the precision and rationality of primary farmland zoning. We further analyzed the farmland loss and its underlying driving forces among various zones using sensitivity analysis. The result shows 
that urban expansion is the key threat to the stability of farmland at ODZ and KDZ, whereas ecological degradation and reforestation are the main reasons for farmland loss at RDZ and FDZ. Moreover, the disparity of the main function among zones will also influence regional farmland protection in the future.

BNs are able to incorporate prior knowledge into new observed evidence, allowing us to integrate farmland historical changes and multi-level quantitative suitability/economic factors for optimizing the allocation of primary farmland. As a nonparametric and non-black-box statistical model, BN models allow us to incorporate different types of data into zoning models and to analyze the sensitivity of each variable easily. All of the above advantages make BN modelling an appropriate method for the simulation of primary farmland zoning in China.

To ensure the equitability of regional development and promote the protection initiative, a set of policies and measures should be introduced to the agenda, such as a mechanism for primary farmland compensation, financial transfer payment, accelerating the land approval registration and a land development rights transfer process. A reasonable zoning system of farmland protection should be constructed to ensure the quantity and quality of national primary farmland. Additionally, farmland protection zoning is a hierarchical decision-making system in China. Local governments must combine the farmland protection policies and DPZ strategy at the national level with land use planning at the local level to achieve a no-net loss of farmland in each region.

Author Contributions: Jianhua He had the original idea for the study, and both coauthors conceived and designed the methodology. Xiaodong Guan performed the experiment and drafted the manuscript, which was revised by Jianhua He and Yan Yu. All authors have read and approved the final manuscript.

Conflicts of Interest: The authors declare no conflict of interest.

\section{References}

1. Duke, J.M.; Lynch, L. Gauging support for innovative farmland preservation techniques. Policy Sci. 2007, 40, 123-155. [CrossRef]

2. Liu, X.; Li, X.; Tan, Z.; Chen, Y. Zoning farmland protection under spatial constraints by integrating remote sensing, GIS and artificial immune systems. Int. J. Geogr. Inf. Sci. 2011, 25, 1829-1848. [CrossRef]

3. Lichtenberg, E.; Ding, C. Local officials as land developers: Urban spatial expansion in China. J. Urban Econ. 2009, 66, 57-64. [CrossRef]

4. He, J.; Liu, Y.; Yu, Y.; Tang, W.; Xiang, W.; Liu, D. A counterfactual scenario simulation approach for assessing the impact of farmland preservation policies on urban sprawl and food security in a major grain-producing area of China. Appl. Geogr. 2013, 37, 127-138. [CrossRef]

5. Daniels, T.; Bowers, D. Holding Our Ground: Protecting America's Farms and Farmland; Island Press: Washington, DC, USA, 1997.

6. Dorfman, J.H.; Barnett, B.J.; Bergstrom, J.C.; Lavigno, B. Searching for farmland preservation markets: Evidence from the Southeastern US. Land Use Policy 2009, 26, 121-129. [CrossRef]

7. Lynch, L.; Gray, W.; Geoghegan, J. Are farmland preservation program easement restrictions capitalized into farmland prices? What can a propensity score matching analysis tell us? Appl. Econ. Perspect. Policy 2007, 29, 502-509. [CrossRef]

8. Lichtenberg, E.; Ding, C. Assessing farmland protection policy in China. Land Use Policy 2008, 25, 59-68. [CrossRef]

9. Huang, Q.; Lu, J.; Li, M.; Chen, Z.; Li, F. Developing planning measures to preserve farmland: A case study from China. Sustainability 2015, 7, 13011-13028. [CrossRef]

10. Zhong, T.; Huang, X.; Zhang, X.; Scott, S.; Wang, K. The effects of basic arable land protection planning in Fuyang County, Zhejiang Province, China. Appl. Geogr. 2012, 35, 422-438. [CrossRef]

11. Francis, C.A.; Hansen, T.E.; Fox, A.A.; Hesje, P.J.; Nelson, H.E.; Lawseth, A.E.; English, A. Farmland conversion to non-agricultural uses in the US and Canada: Current impacts and concerns for the future. Int. J. Agric. Sustain. 2012, 10, 8-24. [CrossRef]

12. Zvomuya, F.; Janzen, H.H.; Larney, F.J; Olson, B.M. A long-term field bioassay of soil quality indicators in a semiarid environment. Soil Sci. Soc. Am. J. 2008, 72, 683-692. [CrossRef] 
13. Song, W.; Pijanowski, B.C.; Tayyebi, A. Urban expansion and its consumption of high-quality farmland in Beijing, China. Ecol. Indic. 2015, 54, 60-70.

14. King, R.N.; Lamb, J. Using land evaluation and site assessment (LESA) for farmland protection planning: A case study. J. Ext. 2001, 39, 4.

15. Hoobler, B.M.; Vance, G.F.; Hamerlinck, J.D.; Munn, L.C.; Hayward, J.A. Applications of land evaluation and site assessment (LESA) and a geographic information system (GIS) in East Park County, Wyoming. J. Soil Water Conserv. 2003, 58, 105-112.

16. Dung, E.J.; Sugumaran, R. Development of an agricultural land evaluation and site assessment (LESA) decision support tool using remote sensing and geographic information system. J. Soil Water Conserv. 2005, 60, 228-235.

17. Tulloch, D.L.; Myers, J.R.; Hasse, J.E.; Parks, P.J.; Lathrop, R.G. Integrating GIS into farmland preservation policy and decision making. Landsc. Urban Plan. 2003, 63, 33-48. [CrossRef]

18. Machado, E.A.; Stoms, D.M.; Davis, F.W.; Kreitler, J. Prioritizing farmland preservation cost-effectively for multiple objectives. J. Soil Water Conserv. 2006, 61, 250-258.

19. Qian, F.K. Research of the basic farmland evaluation and protection. Adv. Mater. Res. 2014, 869, 88-90. [CrossRef]

20. Daniels, T.L. Policies to preserve prime farmland in the USA: A comment. J. Rural Stud. 1990, 6, 331-336. [CrossRef]

21. Mathews, L.G.; Rex, A. Incorporating scenic quality and cultural heritage into farmland valuation: Results from an Enhanced LESA Model. In Proceedings of the 2010 Annual Meeting, Denver, CO, USA, 25-27 July 2010.

22. Li, X.; Yeh, A.G.O. Zoning land for agricultural protection by the integration of remote sensing, GIS, and cellular automata. Photogramm. Eng. Remote Sens. 2001, 67, 471-478.

23. Zhang, R.; Li, J.; Du, Q.; Ren, F. Basic farmland zoning and protection under spatial constraints with a particle swarm optimisation multiobjective decision model: A case study of Yicheng, China. Environ. Plan. B Plan. Des. 2015, 42, 1098-1123. [CrossRef]

24. Liu, T.; Liu, H.; Qi, Y. Construction land expansion and cultivated land protection in urbanizing China: Insights from national land surveys, 1996-2006. Habitat Int. 2015, 46, 13-22. [CrossRef]

25. Wu, Y.; Peng, Y.; Zhang, X.; Skitmore, M.; Song, Y. Development priority zoning (DPZ)-led scenario simulation for regional land use change: The case of Suichang County, China. Habitat Int. 2012, 36, 268-277. [CrossRef]

26. Liu, Y.; Yang, Z. New progress and its prospects of land resources sciences research in China. J. Nat. Resour. 2008, 23, 353-360.

27. Su, S.; Jiang, Z.; Zhang, Q.; Zhang, Y. Transformation of agricultural landscapes under rapid urbanization: A threat to sustainability in Hang-Jia-Hu region, China. Appl. Geogr. 2011, 31, 439-449. [CrossRef]

28. Xie, H.; Wang, P.; Yao, G. Exploring the dynamic mechanisms of farmland abandonment based on a spatially explicit economic model for environmental sustainability: A case study in Jiangxi Province, China. Sustainability 2014, 6, 1260-1282. [CrossRef]

29. Pearl, J. Causality: Models, Reasoning, and Inference, 2nd ed.; Cambridge University Press: New York, NY, USA, 2009.

30. Frayer, J.; Sun, Z.; Müller, D.; Munroe, D.K.; Xu, J. Analyzing the drivers of tree planting in Yunnan, China, with Bayesian networks. Land Use Policy 2014, 36, 248-258. [CrossRef]

31. Newton, A.; Marshall, E.; Schreckenberg, K.; Golicher, D.; te Velde, D.W.; Edouard, F.; Arancibia, E. Use of a Bayesian belief network to predict the impacts of commercializing non-timber forest products on livelihoods. Ecol. Soc. 2007, 11, 24.

32. Sun, Z.; Müller, D. A framework for modeling payments for ecosystem services with agent-based models, Bayesian belief networks and opinion dynamics models. Environ. Model. Softw. 2013, 45, 15-28. [CrossRef]

33. Prato, T. Multiple attribute evaluation of landscape management. J. Environ. Manag. 2000, 60, 325-337. [CrossRef]

34. Alix-Garcia, J.; Kuemmerle, T.; Radeloff, V.C. Prices, land tenure institutions, and geography: A matching analysis of farmland abandonment in post-socialist Eastern Europe. Land Econ. 2012, 88, 425-443. [CrossRef] 
35. Smith, C.S.; Howes, A.L.; Price, B.; McAlpine, C.A. Using a Bayesian belief network to predict suitable habitat of an endangered mammal-The Julia Creek dunnart (Sminthopsis douglasi). Biol. Conserv. 2007, 139, 333-347. [CrossRef]

36. Ticehurst, J.L.; Curtis, A.; Merritt, W.S. Using Bayesian networks to complement conventional analyses to explore landholder management of native vegetation. Environ. Model. Softw. 2011, 26, 52-65. [CrossRef]

37. Aalders, I. Modeling land-use decision behavior with Bayesian belief networks. Ecol. Soc. 2008, 13, 439-461.

38. Lynch, A. Is it good to be green? Assessing the ecological results of county green infrastructure planning. J. Plan. Educ. Res. 2016, 36, 90-104. [CrossRef]

39. Pollino, C.A.; Woodberry, O.; Nicholson, A.; Korb, K.; Hart, B.T. Parameterisation and evaluation of a Bayesian network for use in an ecological risk assessment. Environ. Model. Softw. 2007, 22, 1140-1152. [CrossRef]

(C) 2016 by the authors; licensee MDPI, Basel, Switzerland. This article is an open access article distributed under the terms and conditions of the Creative Commons Attribution (CC-BY) license (http://creativecommons.org/licenses/by/4.0/). 